\title{
Elastic and Anelastic Properties of Amorphous Thin Films
}

\author{
H. Mizubayashi \\ Institute of Materials Science, University of Tsukuba, Tsukuba 305, Japan
}

\begin{abstract}
The interesting non-linear elastic and anelastic properties recently found in the metal-metal and the metal-metalloid amorphous alloys will be reported. The Young's modulus $E_{\mathrm{d}}$ measured by means of the vibrating reed method with the strain amplitude $\varepsilon_{\mathrm{t}} \leftrightharpoons 10^{-6}$ is found to be lower than $E_{\mathrm{s}}$ in the frequency $f$ range below (10 ${ }^{3} \sim$ $\left.10^{4}\right) \mathrm{Hz}$, showing a minimum at around $10^{2} \mathrm{~Hz}$, and to increase beyond $E_{\mathrm{s}}$ in the $f$ range above $\left(10^{3} \sim 10^{4}\right) \mathrm{Hz}$, where $E_{\mathrm{s}}$ denotes the Young's modulus in linear elasticity observed for the static tensile or bending tests. These results suggest that a certain resonant anelastic-process is excited under alternating strain in the $f$ range below (10 3 $\left.\sim 10^{4}\right) \mathrm{Hz}$. The $\varepsilon_{\mathrm{t}}$ dependence of $E_{\mathrm{d}}$ measured at $f \fallingdotseq 10^{2} \mathrm{~Hz}$ shows that $E_{\mathrm{d}}$ increases towards $E_{\mathrm{s}}$ with increasing $\varepsilon_{\mathrm{t}}$. Further, for the measurements at $f \fallingdotseq 10^{2} \mathrm{~Hz}$ with $\varepsilon_{\mathrm{t}} \fallingdotseq 10^{-6}$, an increase in $E_{\mathrm{d}}$ is also found but under passing an electric direct current (PEC) with $10^{7} \mathrm{~A} / \mathrm{m}^{2}$, suggesting that internal stress is induced under PEC. These results suggest the view that a certain cluster of many atoms undergoes a resonant motion under alternating strain, and also yields internal stress due to the concentration of the electromigration force through a collective motion under PEC. The effective charge number $Z^{*}$ which measures internal stress induced under PEC is found to be the order of $10^{5}$ for all the amorphous alloys. The number of atoms involved in the above cluster is estimated to lie between $10^{2}$ and $10^{5}$
\end{abstract}

\section{INTRODUCTION}

The mechanical properties of amorphous alloys have been investigated mostly on thin-tape or thin-film specimens prepared by melt-quenching. For plastic deformation of amorphous alloys (see [1] and references therein), homogeneous deformation is observed above the transition temperature $T_{\mathrm{c}}$ of 0.7 to $0.8 T_{\mathrm{g}}\left(T_{\mathrm{g}}\right.$, the glass transition temperature), where deformation is viscous. Below $T_{\mathrm{c}}$, plastic deformation takes place through localized slips, where flow stress is not sensitive to temperature and the strain rate. In the microstrain range below yielding, a localized shear deformation (abbreviated as LSD) plays an important role. The present paper deals with the recent topics on the elastic and anelastic responses listed in Table 1.

It is widely observed that in the tensile tests, amorphous alloys show linear elasticity in the low strain ( $\left.\varepsilon_{t}\right)$ range below $(0.4 \sim 1) \%$ and a non-linear increase in anelastic strain in the high strain range but below yielding, $(0.4 \sim 1) \%<\varepsilon_{\mathrm{t}}<$ about $2 \%$, ('tensile test' in Table I). For linear elasticity in the low strain range, it is known that both the Young's modulus and the shear modulus of amorphous alloys are lower by about 20 to $40 \%$ than those in the crystalline state but the bulk modulus is similar between the amorphous and crystalline states [2-13]. The pioneer computer simulation study [6] shows that elastic deformation in the amorphous structure is not uniform in an atomic scale, where the LSD in a small region containing several atoms (which will be referred to as the deformable unit, below) is suggested to be responsible for the low Young's modulus and the low shear modulus in the amorphous state. For the non-linear increase in anelastic strain found in the high strain range (e.g., [14]), the computer simulation $[1,15,16]$ shows that in the high strain range, the LSD expands in a roughly spherical region of several atomic distances. Meanwhile, in the X-ray study, the bond-orientational anisotropy is found in the amorphous alloys 
annealed under stretching [17-19]. Such an anisotropy is expected when the LSD attained during annealing under stretching partly remains after unloading following the annealing. So far the outline of the elastic and anelastic responses of amorphous alloys observed in the tensile tests may be explained by the LSDs and their evolution: The LSD in every deformable unit increases linearly with stress in the low strain range below $(0.4 \sim 1) \%$. In the high strain range above $(0.4 \sim 1) \%$, the LSD in every deformable unit goes up to a certain saturation value and then, a size of every deformable unit starts to expand, giving rise to the non-linear increase in anelastic strain. Experimentally, however, the knowledge on the LSD in the deformable unit is very limited.

Table 1 The elastic and anelastic responses of amorphous alloys in the pre-yield microstrain range below $T_{\mathrm{c}}$. For a tensile test, $\varepsilon_{\mathrm{t}}$ is strain, $E_{\mathrm{s}}$ the static Young's modulus found in linear elasticity for $\varepsilon_{\mathrm{t}}<(0.4 \sim 1) \%$, and $\left(E_{\mathrm{s}}\right)_{\text {cry }} E_{\mathrm{s}}$ in the crystalline state. For a vibrating reed measurements, $\varepsilon_{\mathrm{t}}$ is the strain amplitude, $f$ the vibrational frequency, $E_{\mathrm{d}}$ the dynamic Young's modulus deduced from $f$, and PEC an abbreviation of 'passing electric current'. See Fig.3 or Fig.4 for $\varepsilon_{\mathrm{A}}$ and $\varepsilon_{\mathrm{Y}}$.

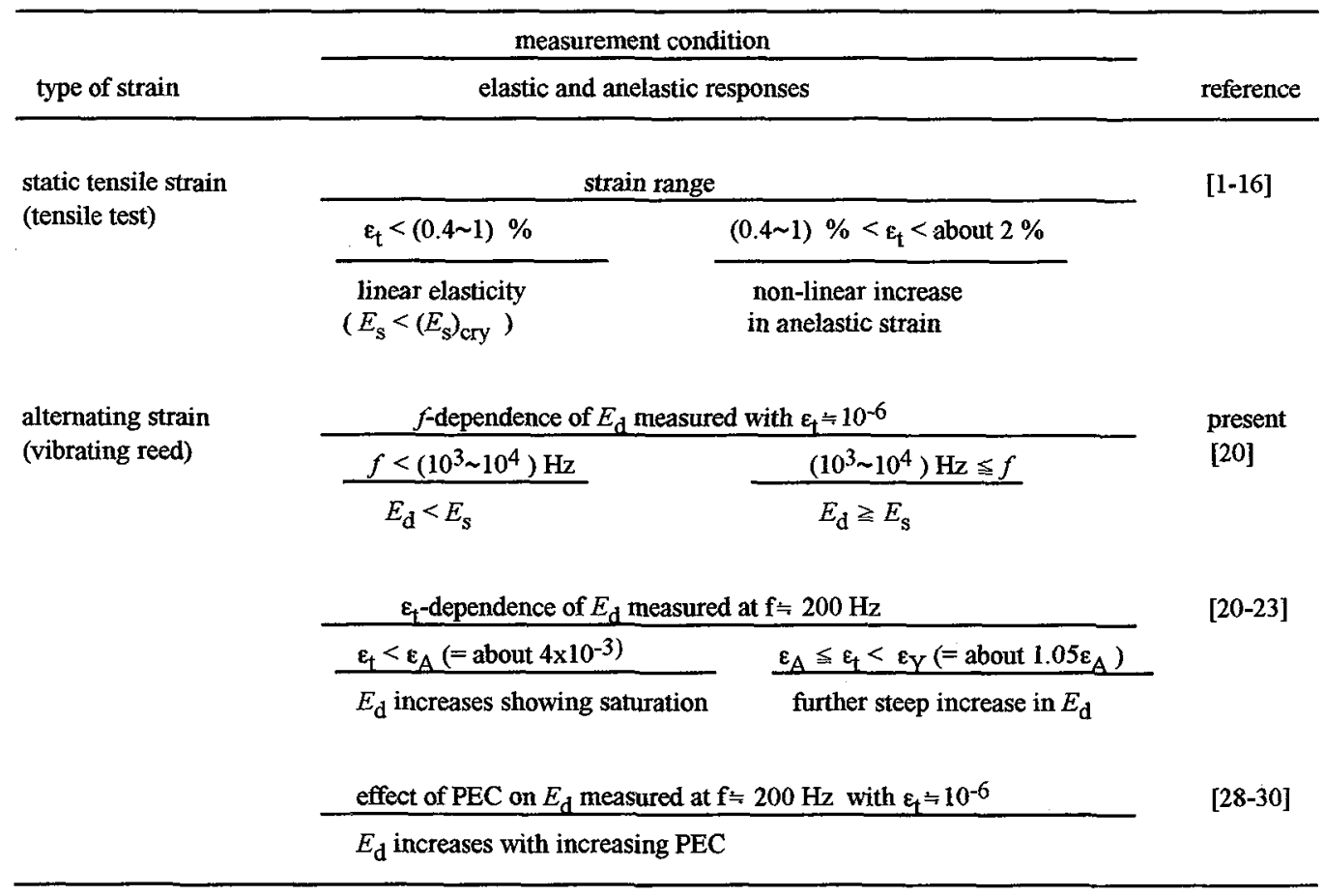

Since anelastic strain can vary depending on the relaxation time of the anelastic process and the measurement frequency, a vibrating reed measurement is expected to give an insight into the LSD in the deformable units. The preliminary vibrating reed study for amorphous $\mathrm{Pd}_{80} \mathrm{Si}_{20}$ [20] shows that $E_{\mathrm{d}}$ measured with $\varepsilon_{\mathrm{t}}=10^{-6}$ is lower than $E_{\mathrm{s}}$ in the frequency range below $\left(10^{3} \sim 10^{4}\right) \mathrm{Hz}$ and increases beyond $E_{\mathrm{s}}$ for the higher frequencies ('f-dependence of $E_{\mathrm{d}}$ ' for 'vibrating reed' in Table I), where $\varepsilon_{\mathrm{t}}$ is the strain amplitude, $E_{\mathrm{d}}$ the dynamic Young's modulus determined from the resonant frequency $f$ of a reed, and $E_{\mathrm{s}}$ the static Young's modulus in linear elasticity observed in the low strain range for the tensile tests. This result is surprising, because for anelastic materials as well as amorphous alloys, $E_{\mathrm{d}}$ should be higher than $E_{\mathrm{s}}$ when a resonant anelastic-process is not involved. The vibrating reed study at $f=10^{2} \mathrm{~Hz}$ on the $\varepsilon_{\mathrm{t}}$ dependence of the relative change in $E_{\mathrm{d}}$ for various amorphous alloys [20-23] shows that $E_{\mathrm{d}}$ increases showing saturation in the strain range below about $4 \times 10^{-3}$ (' $\varepsilon_{\mathrm{t}}$-dependence of $E_{\mathrm{d}}$ ' for 'vibrating reed' in Table I). It is noted that in the above strain range, however, linear elasticity is observed in the tensile tests. 
These results suggest that a certain resonant anelastic-process takes place under alternating strain in the $f$

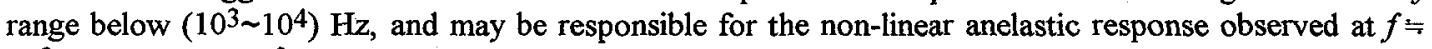
$10^{2} \mathrm{~Hz}$ for $\varepsilon_{\mathrm{t}}<4 \times 10^{-3}$. The fact that the above frequency range is so much lower than the Debye frequency presumably suggests that the resonant anelastic-process is associated with a large number of atoms.

Recently, in the electrical resistivity measurements on the structural relaxation and the crystallization processes in amorphous alloys, it is found that these processes are enhanced under passing an electric direct current (abbreviated as PEC) with the current density $i_{\mathrm{d}}$ of $10^{7} \mathrm{~A} / \mathrm{m}^{2}$, suggesting that the concentration of the electromigration force takes place through a probable collective motion of may atoms under PEC ([24-27] and see the section 3). The combination of the above results found under PEC and ' $\varepsilon_{\mathrm{t}}$-dependence of $E_{\mathrm{d}}$ ' for 'vibrating reed' in Table I predicts that $E_{\mathrm{d}}$ measured at $f \fallingdotseq 10^{2} \mathrm{~Hz}$ with $\varepsilon_{\mathrm{t}} \div 10^{-6}$ can be modified by PEC. The preliminary study of the effect of PEC on $E_{\mathrm{d}}$ shows that the prediction is the case [28-30] ('effect of PEC on $E_{\mathrm{d}}$ ' for 'vibrating reed' in Table I). The fact that the current density here is so low as $10^{7} \mathrm{~A} / \mathrm{m}^{2}$ suggests that a number of atoms are associated with the probable collective motion. That is, both the characteristic anelastic behaviors found under alternating strain and those under PEC suggest that a certain collective motion of many atoms can be excited in amorphous alloys. The following sections are devoted to these topics.

\section{EFFECTS OF ALTERNATING STRAIN}

Prior to the vibrating reed measurements, we carried out the tensile tests and the three-point bending tests in the strain range near or below $10^{-3}$, because such a static test in the low strain range has been very limited before. Figure 1(a) shows an example of the tensile tests for the melt-spun amorphous $\operatorname{Pd}_{80} \operatorname{Si}_{20}(\mathrm{a}-$ $\mathrm{Pd}_{80} \mathrm{Si}_{20}$ ) specimens, where linear elasticity is observed in the present strain $\varepsilon_{\mathrm{t}}$ range below about $35 \times 10^{-4}$.
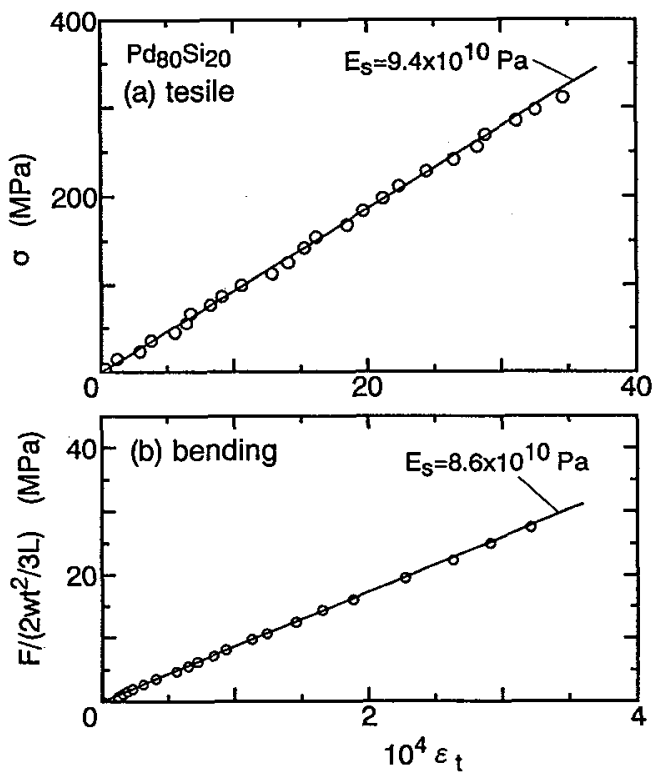

Figure 1. Examples of (a) the tensile and (b) the threepoints bending measurements of a-Pd $\mathrm{Pd}_{80} \mathrm{Si}_{20}$ which were carried out at room temperature (RT). In (b), $F, w, t$ and $L$ denote the load applied to and the width, thickness and gage length of a specimen, respectively (typically, $w=1 \mathrm{~mm}, t=20$ $\mu \mathrm{m}$ and $L=20 \mathrm{~mm}$ )

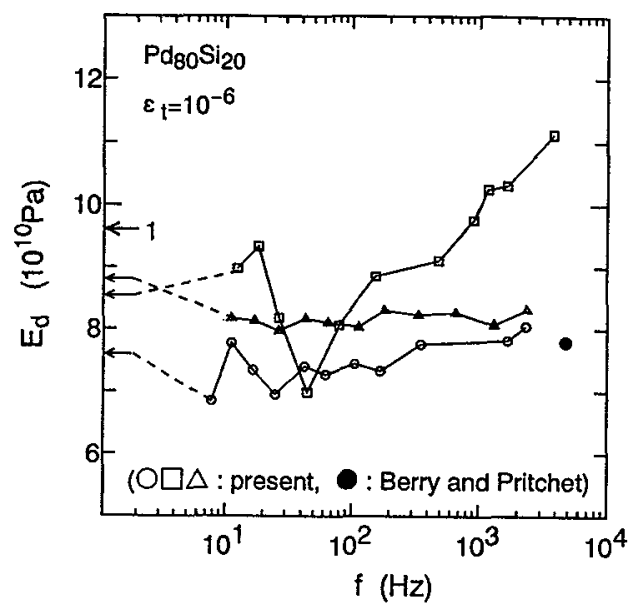

Figure 2. Examples for the $f$ dependence of $E_{\mathrm{d}}$ observed for three a- $\mathrm{Pd}_{80} \mathrm{Si}_{20}$ specimens, where the dynamic Young's modulus $E_{\mathrm{d}}$ is determined from the resonant frequency $f$ of a clamped-free specimen measured with the strain amplitude $\varepsilon_{\mathrm{t}}$ of $10^{-6}$ at RT (see [20] for details). The thin arrows denote the static Young's modulus $E_{\mathrm{s}}$ found in Fig. 1(b). The bold arrow 1 denotes $E_{\mathrm{s}}$ found in Fig. 1(a). 
For the five specimens measured, the values of the static Young's modulus $E_{\mathrm{s}}$ lay between 8.9 and $10.3 \times 10^{10} \mathrm{~Pa}$, where the mean value is $9.6 \pm 0.7 \times 10^{10} \mathrm{~Pa}$. The present value of $E_{\mathrm{s}}$ is slightly higher than the values of $E_{\mathrm{s}}$ reported for a-Pd80 $\mathrm{Si}_{20} ; 6.7$ [5], 8.0 [12] and 8.8 [13] x1010 $\mathrm{Pa}$. Figure 1(b) shows an example of the three-points bending tests of $\mathrm{a}^{-} \mathrm{Pd}_{80} \mathrm{Si}_{20}$ in the strain range below about $4 \times 10^{-4}$. In Fig. 1(b), although the strain range is limited, linear elasticity is again observed for the bending tests, where the values of $E_{\mathrm{s}}$ observed for the three specimens lay between 7.6 and $8.8 \times 10^{10} \mathrm{~Pa}$ (see the thin arrows in Fig.2). The values of $E_{\mathrm{s}}$ found in the bending tests are slightly lower than the values of $E_{\mathrm{s}}$ found in the tensile tests, presumably reflecting that a bending test is more sensitive to the surface roughness of a specimen than a tensile test. After taking into account the difference in the test conditions, one can say that the elastic and anelastic responses under static bending strain are the same to those under static tensile strain.

Figure 2 shows the preliminary results for the measurement frequency $f$ dependence of the dynamic Young's modulus $E_{\mathrm{d}}$ observed for the three a- $\mathrm{Pd}_{80} \mathrm{Si}_{20}$ specimens, which were measured by adjusting the gage length of a vibrating reed, where the strain amplitude $\varepsilon_{\mathrm{t}}$ during the measurements was $10^{-6}$. In Fig.2, $E_{\mathrm{d}}$ reported for $\mathrm{a}_{-} \mathrm{Pd}_{82} \mathrm{Si}_{18}[9]$ is also plotted, which lies nearby the present data. The $f$ vs. $E_{\mathrm{d}}$ data are slightly different among the three specimens, presumably reflecting that the surface roughness is not equal among the three specimens. Apart from the minor difference, in general, $E_{\mathrm{d}}$ is lower than $E_{\mathrm{s}}$ in the frequency range below $\left(10^{3} \sim 10^{4}\right) \mathrm{Hz}$, showing a minimum at around $10^{2} \mathrm{~Hz}$, and then, increases beyond $E_{\mathrm{s}}$ with increasing $f$. Since the elastic and anelastic responses under static bending strain are the same to those under static tensile strain as mentioned for Fig. 1, the characteristic $f$-dependence of $E_{\mathrm{d}}$ found in Fig.2 is not due to bending strain in the vibrating reed measurements but due to alternating strain. The fact that $E_{\mathrm{d}}$ is lower than $E_{\mathrm{s}}$ for $f$ below $\left(10^{3} \sim 10^{4}\right) \mathrm{Hz}$ suggests that a certain resonant anelastic process is excited under alternating strain in the $f$ range.

Meanwhile, the $\varepsilon_{\mathrm{t}}$ dependence of the relative changes in $E_{\mathrm{d}}$ at around $f \leftrightharpoons 10^{2} \mathrm{~Hz}$ has been compiled for various amorphous alloys including a-Pd ${ }_{80} \mathrm{Si}_{20}$ [20-23], where for a clamped-free composite-reed of a
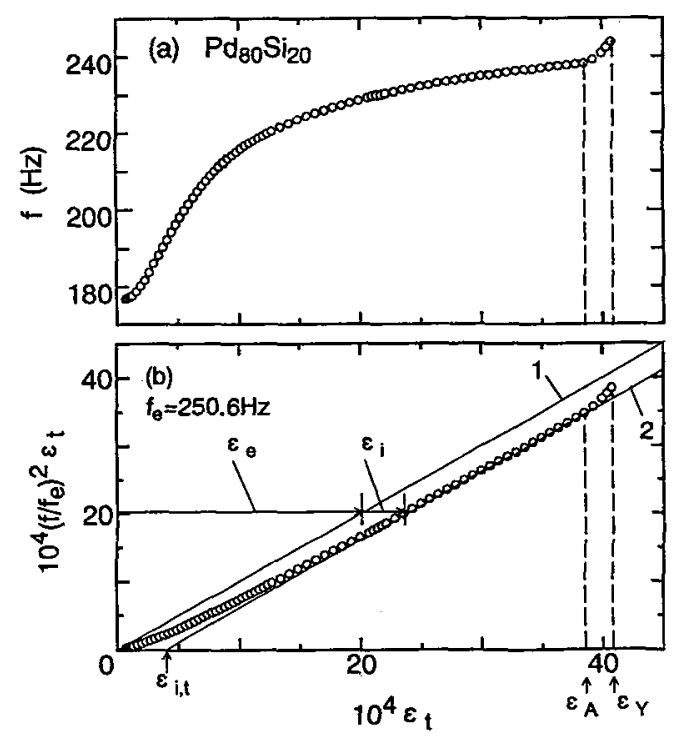

Figure 3. (a) an example of the $\mathrm{e}_{\mathrm{t}}$ dependence of $f$ observed at RT for a-Pd $\mathrm{Pd}_{80} \mathrm{Si}_{20}$, where the gage length $L$ of a clamped-free composite-reed is kept at a given value, about $6 \mathrm{~mm}$. (b) a redrawing of (a) but here the normalized stress $\left(f f f_{\mathrm{e}}\right)^{2} \varepsilon_{\mathrm{t}}$ is plotted. See text for details.

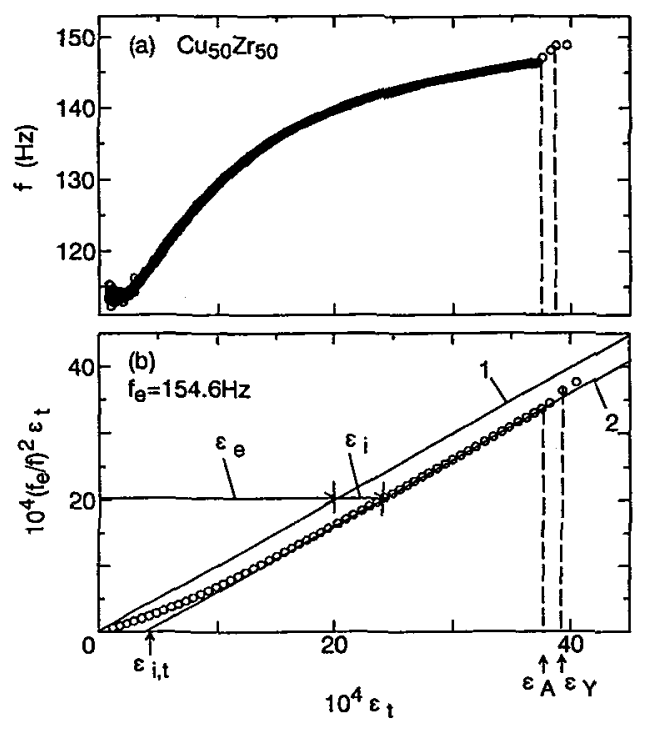

Figure 4. Similar to Fig.3(a) and 3(b) but here the results observed for $\mathrm{a}-\mathrm{Cu}_{50} \mathrm{Zr}_{50}$ are shown. 
given gage length, the $\varepsilon_{\mathrm{t}}$ dependence of $f$ is measured in the strain range below about $40 \times 10^{-4}$. Figure 3(a) shows an example of the $\varepsilon_{\mathrm{t}}$ dependence of $f$ observed for a-Pd $\mathrm{Pd}_{80} \mathrm{Si}_{20}$, where an increase and saturation of $f$ for $\varepsilon_{\mathrm{t}}$ below $\varepsilon_{\mathrm{A}}\left(\varepsilon_{\mathrm{A}} \doteqdot 39 \times 10^{-4}\right.$, here) and an abrupt increase in $f$ for $\varepsilon_{\mathrm{t}}$ between $\varepsilon_{\mathrm{A}}$ and $\varepsilon_{\mathrm{Y}}\left(\varepsilon_{\mathrm{Y}} \doteqdot 1.05 \varepsilon_{\mathrm{A}}\right)$ can be seen. For $\varepsilon_{\mathrm{t}}$ beyond $\varepsilon_{\mathrm{Y}}, f$ changes over to decrease and the prolonged vibrations causes the fatigue failure of specimens, suggesting that micro-yielding starts (not shown here). On the other hand, when $\varepsilon_{\mathrm{t}}$ stays below $\varepsilon_{Y}$, the $\varepsilon_{t}$ dependence of $f$ is reproducible. The internal friction remains almost constant for $\varepsilon_{t}$ below $\varepsilon_{A}$, and shows a steep increase for $\varepsilon_{t}$ above $\varepsilon_{A}$ (see Fig. 1(b) in [23] but for a-Cu $\mathrm{Cu}_{50} \mathrm{Zr}_{50}$ ). These anelastic responses observed for $\varepsilon_{\mathrm{t}}$ below $\varepsilon_{\mathrm{Y}}$ remain almost unchanged for the wide temperature range between 80 and $400 \mathrm{~K}$ (not shown here).

From the saturation behavior of $f$ found in the strain range below $\varepsilon_{\mathrm{A}}$, we estimated the ultimate value $f_{\mathrm{e}}$ and then, deduced the normalized stress $\left(f / f_{\mathrm{e}}\right)^{2} \varepsilon_{\mathrm{t}}$ vs. $\varepsilon_{\mathrm{t}}$ relation shown in Figure 3(b) from the data shown in Fig.3(a). In Fig.3(b), the observed non-linear elasticity is assumed to consist of the constituent linear elasticity with $f=f_{\mathrm{e}}$ giving $\varepsilon_{\mathrm{e}}$ in $\varepsilon_{\mathrm{t}}$ and the constituent non-linear anelasticity associated with $\varepsilon_{\mathrm{i}}$ in $\varepsilon_{\mathrm{t}}$, where $\varepsilon_{\mathrm{i}, \mathrm{t}}$ is the saturation value of $\varepsilon_{\mathrm{i}}$ found at $\varepsilon_{\mathrm{t}}=\varepsilon_{\mathrm{A}}$, here $\varepsilon_{\mathrm{i}, \mathrm{t}} \div 0.11 \varepsilon_{\mathrm{A}}$. The abrupt increase in $f$ for $\varepsilon_{\mathrm{t}}$ above $\varepsilon_{\mathrm{A}}$ seen in Fig.3(a) is explained as the abrupt decrease in $\varepsilon_{\mathrm{i}}$ in Fig.3(b). $f_{\mathrm{e}}$ is slightly higher than $f$ calculated for a vibrating reed with $E_{\mathrm{S}}$ (see [20] for details). Figures 4(a) and 4(b) are similar to Fig.3(a) and $3(\mathrm{~b})$, but here the results observed for $\mathrm{a}-\mathrm{Cu}_{50} \mathrm{Zr}_{50}$ [23] are shown. The characteristic $\varepsilon_{t}$ dependence of $f$ and the steep increase in the internal friction for $\varepsilon_{\mathrm{t}}$ above $\varepsilon_{\mathrm{A}}$ are commonly observed for a-Cu $\mathrm{Cu}_{50} \mathrm{Zr}_{50}$ [23], a- $\mathrm{Cu}_{50} \mathrm{Ti}_{50}[21,22]$ and $\mathrm{a}-\mathrm{Pd}_{80} \mathrm{Si}_{20}[20]$.

In the tensile tests in the pre-yield microstrain range [14], the appearance of hysteretic strain is detected in the higher strain range in which the non-linear increase in anelastic strain is observed. On the other hand, in the vibrating reed measurements for the $\varepsilon_{\mathrm{t}}$ dependence of $f$, the steep increase in the internal friction is observed for $\varepsilon_{\mathrm{t}}$ above $\varepsilon_{\mathrm{A}}$, suggesting that expansion in the size of the deformable units

reported in the computer simulation study $[1,15,16]$ starts for $\varepsilon_{t}$ beyond $\varepsilon_{A}$, in other words, the size of the deformable units remains unchanged for $\varepsilon_{t}$ below $\varepsilon_{A}$. Then, the characteristic anelastic responses found under alternating strain can be explained as follows: For $\varepsilon_{t}$ below $\varepsilon_{A}$, the LSD in every deformable unit is enhanced due to a resonant motion of a certain cluster of many atoms as a whole under alternating strain, and shows saturation with increasing stress. For $\varepsilon_{\mathrm{t}}$ beyond $\varepsilon_{\mathrm{A}}$, expansion in the size of the deformable units starts, and gives rise to the complementary decrease in the size of the above clusters, resulting in a decrease in the resonant anelastic-process. This model will further be discussed in the section 4 .

\section{EFFECTS OF PASSING ELECTRIC CURRENT}

As mentioned in the section 1 , both the structural relaxation and the crystallization processes of various amorphous alloys are found to be accelerated under PEC with the current density $i_{\mathrm{d}}$ of $10^{7} \mathrm{~A} / \mathrm{m}^{2}[24-$ $27,31,32]$. For the crystallization process, the homogeneous nucleation process is accelerated under PEC [27]. Meanwhile, it has been reported that the homogeneous nucleation process is accelerated under uniaxial stress $[33,34]$. The combination of these results suggests that PEC induces internal stress in amorphous alloys, the order of $0.1 \mathrm{GPa}$ under PEC with $i_{\mathrm{d}}$ of $5 \times 10^{7} \mathrm{~A} / \mathrm{m}^{2}$, and predicts that $E_{\mathrm{d}}$ can be modified under PEC when the vibrating reed measurements are carried out at $f \div 10^{2} \mathrm{~Hz}$ with $\varepsilon_{\mathrm{t}} \fallingdotseq 10^{-6}$.

Figure 5 shows an example of the effect of PEC on the resonant frequency $f$ which was measured at $f$ $\fallingdotseq 200 \mathrm{~Hz}$ with $\varepsilon_{\mathrm{t}} \fallingdotseq 10^{-6}$ for an a- $\mathrm{Cu}_{50} \mathrm{Zr}_{50}$ reed specimen (see Fig. 1 in [28] for the measurement setup). $f$ under PEC was measured in an $\mathrm{He}$ gas atmosphere of $10^{2} \mathrm{~Pa}$ to minimize the effect of joule heating (the open symbols in Fig.5). An increase in the specimen temperature under PEC was measured separately and then, the change in $f$ due to the increase in the specimen temperature under PEC (the filled symbols in Fig.5) was estimated from the $f$ vs. temperature data which were also separately measured without PEC. The net increase in $f, \Delta f$, under PEC was estimated after the subtraction of the change in $f$ due to joule heating as shown in Fig. 5 .

Figure 6 shows examples of $\Delta f\left(f_{0}\right.$ observed at $f \div 10^{2} \mathrm{~Hz}$ with $\varepsilon_{\mathrm{t}} \div 10^{-6}$ under PEC for the various aalloys, where $f_{0}$ is $f$ observed without PEC. In the same figure, the $i_{\mathrm{d}}$ vs. $f$ data observed for the crystalline $\mathrm{Ni}-\mathrm{Cr}$ alloy is also shown, where no net-change in $f$ was observed. In contrast, the considerable net- 
increase in $\mathrm{f},\left(\Delta f / f_{0}\right)_{\mathrm{PEC}}$, is commonly found for all the amorphous alloys but the magnitude of $\left(\Delta f / f_{0}\right)_{\mathrm{PEC}}$ depends on the chemical composition of the a-alloys. $\left(\Delta f / f_{0}\right)_{\mathrm{PEC}}$ diminishes after crystallization (not shown here)

Further, for every a-alloy shown in Fig. 6 , the $i_{\mathrm{d}}$ dependence of $\left(\Delta f l f_{0}\right)_{\mathrm{PEC}}$ observed under PEC is found to show good agreement with the $\varepsilon_{\mathrm{t}}$ dependence of $\left(\Delta f / f_{0}\right)_{\varepsilon}$ after scaling the $\varepsilon_{\mathrm{t}}$ axis with a proportional constant $\alpha$ as $\varepsilon_{\mathrm{t}}=\alpha i_{\mathrm{d}}$, where $\left(\Delta f f f_{0}\right)_{\varepsilon}$ denotes an increase in $f$ with increasing $\varepsilon_{\mathrm{t}}$ observed at $f$ $\fallingdotseq 10^{2} \mathrm{~Hz}$ without PEC (see Fig.3(a) and Fig.4(a)). Figure 7 shows an example of the scaling made between the $i_{\mathrm{d}}$ dependence of $\left(\Delta f / f_{0}\right)_{\mathrm{PEC}}$ and the $\varepsilon_{\mathrm{t}}$ dependence of $\left(\Delta f / f_{0}\right)_{\mathrm{E}}$ observed for a-Cu $\mathrm{Cu}_{50} \mathrm{Zr}_{50}$.

After the LSD-model mentioned in the section 2 , the LSD in the deformable units is enhanced under alternating strain and shows saturation with increasing applied stress. The $i_{\mathrm{d}}$ dependence of $\left(\Delta f / f_{0}\right)_{\mathrm{PEC}}$ observed under PEC also suggests that the LSD attained under alternating stress of $\varepsilon_{\mathrm{t}} \fallingdotseq 10^{-6}$ decreases under internal stress induced by PEC. Then, as the first step for the evaluation of the effect of PEC, we assume that the force $F_{\mathrm{PEC}}$ acting on an atom in the deformable unit under PEC may be calibrated by the corresponding force $F_{\varepsilon}$ under increased $\varepsilon_{\mathrm{t}}$.

When an dimensional cross-section of an atom is denoted by $S, F_{\mathrm{e}}$ can be given by,

$$
F_{\varepsilon}=S E \varepsilon_{\mathrm{t}}
$$

where $E \varepsilon_{\mathrm{t}}$ measures tensile stress in a specimen and the elasticity theory is assumed to be applicable to account for $F_{\varepsilon}$. We assume that $F_{\mathrm{PEC}}$ reflects the concentration of the electromigration force [35,36] through a collective motion of many atoms and can be accounted for using the effective charge number $Z^{*}$ as

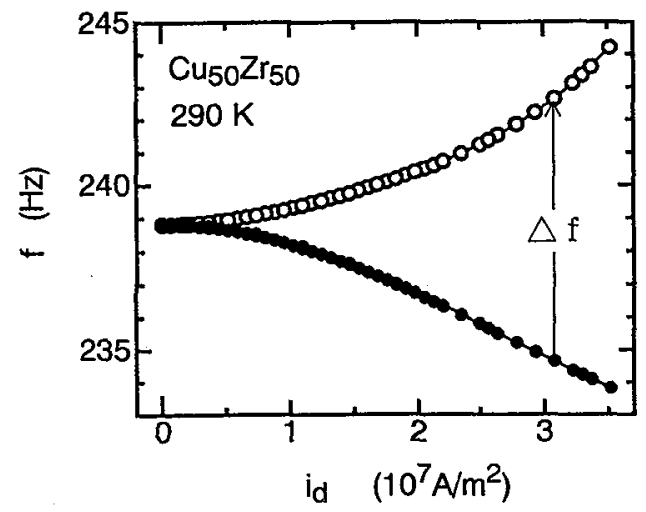

Figure 5. An example of the effect of passing electric current (PEC) on $f$ which was measured for an a$\mathrm{Cu}_{50} \mathrm{Zr}_{50}$ reed specimen at $\varepsilon_{\mathrm{t}} \div 10^{-6}$ : $O$ : the observed changes in $f$ under PEC, : the changes in $f$ due to joule heating. $\Delta f$ denotes the net change in $f$ under PEC.

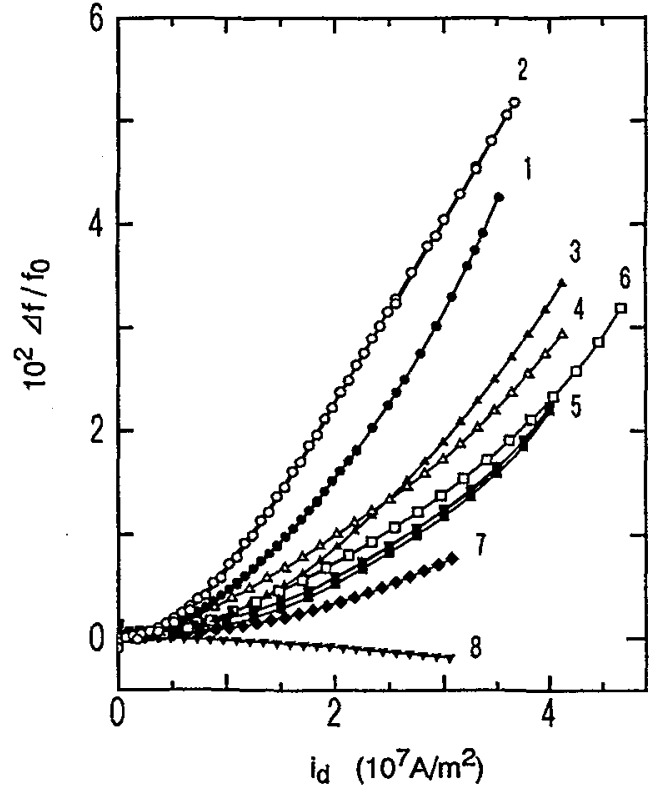

Figure 6. Examples for the net changes in $f$ under PEC, ( $\left.\triangle f f_{0}\right)_{\mathrm{PEC}}$, observed at $\varepsilon_{\mathrm{t}} \leftrightharpoons 10^{-6}$ for the various a-alloys, where $f_{0}$ is $f$ found without PEC ( $200 \mathrm{~Hz}$ here): 1 at room temperature (RT) and 2 at $80 \mathrm{~K}$ for $\mathrm{a}-\mathrm{Cu}_{50} \mathrm{Zr}_{50}, 3$ at RT and 4 at $80 \mathrm{~K}$ for $\mathrm{a}-\mathrm{Cu}_{50} \mathrm{Ti}_{50}, 5$ at $\mathrm{RT}$ and 6 at $80 \mathrm{~K}$ for a- $\left(\mathrm{Cu}_{30} \mathrm{Zr}_{70}\right)_{92.5} \mathrm{Al}_{7.5}, 7$ at RT for a-Pd ${ }_{80} \mathrm{Si}_{20}$. The data observed for the crystalline $\mathrm{Ni}-\mathrm{Cr}$ alloy, 8 at RT, is also shown (see text). 


$$
F_{\mathrm{PEC}}=Z^{*} e \Phi
$$

where $e$ denotes the elementary charge, and $\Phi$ the strength of the electric field in a specimen under PEC. The combination of equations (1) and (2) gives the relationship,

$$
Z^{*}=\alpha S E / e \rho_{\mathrm{R}},
$$

where $\rho_{R}$ denotes the resistivity of the a-alloys. The application of equation (3) to the results shown in Fig. 7 or those observed for the various a-alloys gives $Z^{*}$ listed in Table 2, which is the order of $10^{5}$

The nearly free electron model predicts that the effective charge number of an atom in crystalline metals is the factor of ten [37]. The effective charge number which is accounted for from the enhanced dislocation motion under PEC reported in crystalline metals [38] is an order of magnitude larger than the charge number per atom reported in the crystalline metals [35-37], presumably reflecting that a motion of dislocation corresponds to a correlated motion of many atoms. We assume that $Z^{*}$ measures the concentration of the electromigration force onto the front atom(s) in the probable collected motion of $\xi$ atoms with the charge number $z^{*}$ per atom as

$$
Z^{*}=\xi z^{*}
$$

$\xi$ is expected to vary after annealing of the a-alloys for the structural relaxation and the crystallization at elevated temperatures because of a change in the amorphous structure. Examples for the annealing experiments are shown in Figures $8(\mathrm{a})$ and $8(\mathrm{~b})$, where the change in the length of the specimens $\Delta L / L$ and that in $Z^{*}$ due to annealing observed for a- $\mathrm{Cu}_{50} \mathrm{Zr}_{50}$ are plotted, respectively. $\Delta L / L$ shows a small decrease by about $0.08 \%$ at around $550 \mathrm{~K}$ reflecting a decrease in the free volumes due to the structural relaxation and a steep decrease by about $0.7 \%$ (see Fig. 7 in [23]) due to the crystallization. $Z^{*}$ shows an increase by about $30 \%$ after annealing at $500 \mathrm{~K}$ and then, a monotonous decrease to zero at higher

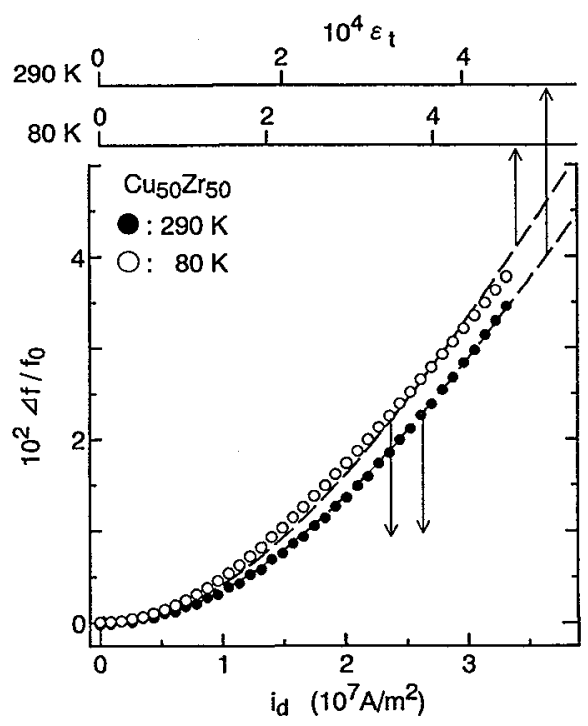

Figure 7. Similar to Fig. 6 but for $\mathrm{a}-\mathrm{Cu}_{50} \mathrm{Zr}_{50}$, the $\left(\Delta f f_{0}\right)_{\mathrm{PEC}}$ vs. $i_{\mathrm{d}}$ data (the symbols, $290 \mathrm{~K}$ and $\bigcirc$ at $80 \mathrm{~K})$ are shown. In the same figure, the $\left(\Delta f l f_{0}\right)_{\varepsilon}$ vs. $\varepsilon_{\mathrm{t}}$ data observed without PEC (the dashed lines) are shown after scaling the $\varepsilon_{\mathrm{t}}$ axis as $\varepsilon_{\mathrm{t}}=\alpha i_{\mathrm{d}}$ with a proportional constant $\alpha$. See text for details.

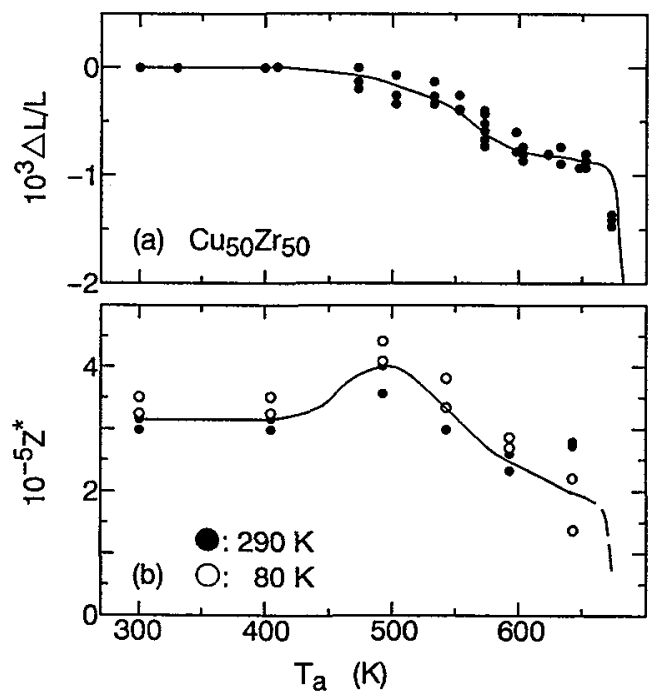

Figure 8. Effects of annealing on (a) the length of specimens $L$ and (b) the effective charge number $Z^{*}$ observed in a- $\mathrm{Cu}_{50} \mathrm{Zr}_{50}$. In (a) $\Delta L / L$ was measured at RT. In (b), the symbols and $O$ were measured at 290 and $80 \mathrm{~K}$, respectively. 
temperatures. $\Delta L / L$ observed in the early stage of the structural relaxation is surmised to reflect annealing out of the vacancy-like free-volumes, here $(\Delta L / L)_{500 \mathrm{~K}}=0.015 \%$ after annealing at $500 \mathrm{~K}$. When the specific volume of the free-volumes annealed out at $500 \mathrm{~K}$ is equal to that of an atomic vacancy, the concentration $\Delta C_{\mathrm{V}}$ of the free-volumes annealed out at $500 \mathrm{~K}$ can be accounted for as $\Delta C_{\mathrm{V}}=3(\Delta L / L)_{500 \mathrm{~K}}$ We suppose that the increase in $\xi$ after annealing at $500 \mathrm{~K}$ is due to annealing out of the vacancy-like free volumes which have interrupted the probable collected motion. Then, one may have the following relationship between $\xi$ and $\Delta C_{\mathrm{v}}$ as

$$
\begin{aligned}
Z^{*}{ }_{500 \mathrm{~K}} / Z_{\mathrm{q}}^{*} & =\xi_{500 \mathrm{~K}} / \xi_{\mathrm{q}} \\
& \sim 1+\xi_{500 \mathrm{~K}} /\left(1 / \Delta C_{\mathrm{v}}\right) \\
& \sim 1+\xi_{500 \mathrm{~K}} \cdot 3(\Delta L / L)_{500 \mathrm{~K}}
\end{aligned}
$$

where $\xi_{\mathrm{q}}$ and $\xi_{500 \mathrm{~K}}$ denote $\xi$ 's found in the as quenched state and after annealing at $500 \mathrm{~K}$, respectively, and $z *$ in equation (4) is assumed to remain unchanged after annealing at $500 \mathrm{~K}$. The application of equation (5) to the observed results of $Z^{*}{ }_{500 \mathrm{~K}} / Z_{\mathrm{q}}^{*}=0.3$ and $(\Delta L / L)_{500 \mathrm{~K}}=0.015 \%$ gives $\xi_{\mathrm{q}} \sim 510$ and $\xi_{500 \mathrm{~K}} \sim 670$ for a-Cu $\mathrm{Cu}_{50} \mathrm{Zr}_{50} . \quad \xi_{\mathrm{q}}$ and $\xi_{500 \mathrm{~K}}$ found here and those for a-Cu $\mathrm{Cu}_{50} \mathrm{Ti}_{50}$ [29] are listed in Table 2, where both $\xi_{q}$ and $\xi_{500 \mathrm{~K}}$ are several hundreds. These results will further be discussed in the section 4 .

Table 2. The effective charge number $Z^{*}$ which measures the effect of $\mathrm{PEC}$, and the number of atoms $\xi$ associated with the probable collective motion which were accounted for from the annealing experiments, where $\xi_{\mathrm{q}}$ and $\xi_{500 \mathrm{~K}}$ denote $\xi^{\prime} \mathrm{s}$ found at the as quenched state and after annealing at $500 \mathrm{~K}$, respectively.

\begin{tabular}{lcccc}
\hline amorphous alloy & $Z^{*}$ & $\xi_{\mathrm{q}}$ & $\xi_{500 \mathrm{~K}}$ & reference \\
\hline $\mathrm{Cu}_{50} \mathrm{Ti}_{50}$ & $2.6 \times 10^{5}$ & 630 & 830 & {$[29]$} \\
$\mathrm{Cu}_{50} \mathrm{Zr}_{50}$ & $3.1 \times 10^{5}$ & 510 & 670 & {$[29]$} \\
$\left(\mathrm{Cu}_{30} \mathrm{Zr}_{70}\right\rangle_{92.5} \mathrm{Al}_{7.5}$ & $\left(10^{5}\right)$ & (not measured) & {$[28]$} \\
$\mathrm{Pd}_{80} \mathrm{Si}_{20}$ & $2.0 \times 10^{5}$ & (not measured) & {$[30]$} \\
\hline
\end{tabular}

\section{DISCUSSION}

The results mentioned in the section 2 suggest that for $\varepsilon_{t}$ below $\varepsilon_{A}$, the LSD in every deformable unit is enhanced by a resonant motion of a certain cluster of many atoms as a whole under alternating strain. The results mentioned in the section 3 also suggest that a certain cluster of many atoms undergoes a collective motion as a whole under PEC. The similarity found between the $i_{\mathrm{d}}$ dependence of $\left(\Delta f / f_{0}\right)_{\mathrm{PEC}}$ under PEC and the $\varepsilon_{\mathrm{t}}$ dependence of $\left(\Delta f / f_{0}\right)_{\varepsilon}$ without PEC (see Fig.7) presumably suggests that the former and the latter probable clusters of many atoms are birds of a feather. Further, a resonant motion of the probable clusters as a whole can be expected when the probable clusters are embedded in the network of the matrix which contains the deformable units. In the above model, we implicitly assume that the LSD in the deformable units takes place at very low stress. Meanwhile, the study on the irradiation induced amorphization [39] reports that homogeneous amorphization is triggered by a shear instability, where the onset of the amorphization is expected to occur when the shear modulus of the irradiated metallic compounds vanishes. Thus, the above implicit assumption may not be unreasonable.

The value of $Z^{*}$ estimated here (see Fig.7 and Table 2) depends on the assumptions mentioned for equations (1) to (3), however, the present value may be not so far from the proper value. For example, from the combination of the acceleration of the crystallization process under uniaxial stress [33,34] and 
that under PEC, $Z^{*}$ is accounted for as $10^{5}$, i.e., the order of $Z^{*}$ here is the same to that of $Z^{*}$ accounted for using equations (1) to (3).

A simple account of $\xi$ from equation (4) yields $\xi=\left(10^{4} \sim 10^{5}\right)$ for the combination of $Z^{*} \fallingdotseq 10^{5}$ found here and $z^{*}=(1 \sim 10)$ reported in crystalline metals, i.e., the calculated value of $\xi$ here is surmised to give the upper bound of $\xi$. On the other hand, in equation (5), we assume that every free-volume which is annealed out below $500 \mathrm{~K}$ serves as an obstacle against the probable collected motion, where the lower bound of $\xi$ is found. Therefore, we tentatively surmise that $\xi$ lies between $10^{2}$ and $10^{5}$. However, the underlying mechanism for the non-linear anelastic responses under alternating strain and that for internal stress induced under PEC are not known at the present. To clarify these issues, the further study is needed.

\section{CONCLUSION}

The elastic and anelastic responses measured for various amorphous alloys suggest the followings: A certain cluster of many atoms undergoes a resonant motion as a whole under alternating strain in the frequency range below $\left(10^{3} \sim 10^{4}\right) \mathrm{Hz}$, giving the model that the above clusters of many atoms are embedded in the network of the matrix which contains the deformable units. Passing an electric direct current (PEC) with $10^{7} \mathrm{~A} / \mathrm{m}^{2}$ induces considerable internal stress through a certain collective motion of many atoms. The cluster of many atoms responsible for the resonant anelastic-process under alternating strain and that responsible for internal stress induced under PEC are surmised to be birds of a feather. The apparent charge number $Z^{*}$ which measures internal stress induced or the concentration of the electromigration force under PEC is found to be the order of $10^{5}$. The number of atoms involved in the above cluster is estimated to lie between $10^{2}$ and $10^{5}$. The underlying mechanism for the resonant anelastic-process under alternating strain and that for internal stress induced under PEC are, however, not know at the present.

\section{Acknowledgements}

The authors are grateful to Dr. H. Tanimoto (Univ. of Tsukuba) for his invaluable helps on the course of experiments. This work is partly supported by a Grant in Aid for Scientific Research from the Ministry of Education, Science and Culture of Japan.

\section{References}

[1] Takeuchi S. and Maeda K., Tech. Rep. of Inst. for Solid State Physics (Univ. Tokyo) A-1730(1986).

[2] Jovanovic S. and Smith C.S., J. Appl. Phys., 32(1961), 121.

[3] Ashby M.F., Nelson A.N. and Centamore R.M.A., Scripta Metall., 4(1970), 715.

[4] Chen H.S., Leamy H.J. and Barmatz M., J. Non-Cryst. Solids, 5(1971), 444.

[5] Masumoto T. and Maddin R., Acta Metall., 19(1971), 725.

[6] Weaire D., Ashby M.F., Logan J. and Weins M.J., Acta Metall., 19(1971), 779.

[7] Golding B., Bagley B.G. and Hsu F.S.L., Phys. Rev. Lett. 29(1972), 68.

[8] Doutoit M. and Chen H.S., Appl. Phys. Lett. 23(1973), 357.

[9] Berry B.S. and Pritchet W.C., J. Appl. Phys. 44(1973), 3122.

[10] Barmatz M. and Chen H.S., Phys. Rev. B, 9(1974), 4073.

[11] Gilman J.J., J. Appl. Phys., 46(1975), 1625.

[12] Chen H.S., Krause J.T. and Coleman E., J. Non-Cryst. Solids, 18(1975), 157.

[13] Davis, L.S., Chou C.-P. Tanner L.E. and Ray R., Scripta Metall., 10(1976), 937.

[14] Hashimoto T., Kobayashi S., Maeda K. and Takeuchi S., 6th Internat. Conf. Strength of Metals and Alloys, edited R.C. Gifkins (Pergamon Press, London, 1982), p.173.

[15] Kobayashi S., Maeda K. and Takeuchi S., Acta Metall., 28(1980), 1641.

[16] Maeda K. and Takeuchi S., Phil. Mag. A, 44(1981), 643. 
[17] Suzuki Y., Haimovich J. and Egami T., Phys. Rev. B, 35(1987), 2162.

[18] Hirscher M., Egami T. and Marinero E.E., J. Appl. Phys., 67, (1990), 4932.

[19] Yan X., Hirscher M., Egami T. and Marinero E.E., Phys. Rev. B, 43, (1991), 9300.

[20] Mizubayashi H., Koyama K. and Horiuchi M., Acta Metall. Mater., submitted.

[21] Mizubayashi H., Okuda S. and Ikeda Y., Phys. Stat. Sol. (a), 116(1989), 633.

[22] Mizubayashi H., Hoshina S. and Okuda S., J. non-cryst. Solids, 117/118(1990), 203.

[23] Mizubayashi H., Kaida M., Otsuka S. and Okuda S., Acta Metall. Mater., 42(1994), 2099.

[24] Mizubayashi H. and Okuda S., Phys. Rev. B, 40(1989), 8057.

[25] Mizubayashi H. and Takemoto R., Defect and Diffusion Forum, 95-98(1993), 1187.

[26] Takemoto R. and Mizubayashi H., Mater. Sci. Engin. A, 179/180(1994), 275.

[27] Takemoto R. and Mizubayashi H., Acta Metall. Mater., 43(1995), 1495.

[28] Mizubayashi $H$. and Takemoto R., J. Alloys and Compounds, 211/212(1994), 340.

[29] Takemoto R., Nagata M. and Mizubayashi H., Acta Metall. Mater., 44(1996), in press.

[30] Mizubayashi H., Takemoto R. and Seki Y., Mater. Sci. Engin. A, (1996), in press.

[31] Allia P., Baricco M., Tiberto P. and Vinai F., Phys. Rev. B, 47(1993), 3118.

[32] Onodera Y., J. Phys.: Condens. Matter, 7(1995), 1235.

[33] Maddin R. and Masumoto T., Mater. Sci. Engng., 9(1972), 153.

[34] Patterson J. and Jones D.R.H, Scripta Metall., 13(1979), 947.

[35] Huntington H.B., in Diffusion in Solid: Recent Developments, edited by A.S. Nowick and J.J. Burton, (Academic Press, New York, 1975), p.303.

[36] d'Heurle F.M. and Ho P.S., in Thin films - Interdiffusion and Reactions, edited by J.M. Poate, K.N. Tu and J.W. Mayer, (Wiley-Interscience, Princeton, 1980), p.243.

[37] Tu K.N., Phys. Rev. B, 45(1992), 1409.

[38] Sprecher A.F., Mannan S.L. and Conrad H., Acta Metall. Mater., 34(1986), 1145.

[39] Okamoto P.R. and Meshii M., Science of Advanced Materls, eds. H. Widersich and M. Meshii, (Metals Park, ASM, 1990), p.33. 